\title{
PERSEPSI PEMUSTAKA TERHADAP ONLINE PUBLIC ACCES CATALOGUE (OPAC) DI PERPUSTAKAAN UNIVERSITAS ISLAM NEGERI ALAUDDIN MAKASSAR
}

\author{
La Ode Rusadi \\ Program Pascasarjana Universitas Islam Negeri Alauddin Makassar \\ rusadilaode61@gmail.com
}

\begin{abstract}
Abstrak: Persepsi pemustaka terhadap Online Public Access Catalogue (OPAC) di Perpustakaan Universitas Islam Negeri Alauddin Makassar sebagai sistem temu balik informasi pemustaka yaitu belum efektif. Hal ini disebabkan oleh pustakawan kurang mensosialisasikan dan memberikan bimbingan kepada pemustaka tentang manfaat OPAC, koneksi jaringan pada komputerOPAC kurang stabil sehingga pemustaka tidak dapat melakukan penelusuran dengan baik, buku yang ada dirak dengan hasil temuan pada mesin pencari OPAC tidak sesuai sehingga berefek pada rasa malas pemustaka untuk menggunakan OPAC, kurangnya ketelitian dalam proses penginputan huruf atau angka dokumen bahan pustaka pada sistem sehingga berakibat tidak ditemukannya dokumen bahan pustaka bila dicari pada mesin pencari OPAC.
\end{abstract}

\section{Kata Kunci: Sistem Temu Balik Informasi; Katalog}

\section{PENDAHULUAN}

Sebelum berkembangnya teknologi informasi, dulu perpustakaan menggunakan katalog buku untuk mendaftar judul-judul koleksi di atas kertas yang dijilid dalam bentuk buku, tetapi kekurangan katalog ini sangat menyusahkan pemustaka dan tidak fleksibel. Kemudian pada tahun 1901-1080 library of congres melakukan launching pencetakan dan penjualan kartu katalog, sebab katalog kertu sangat fleksibel dan praktis, tetapi ternyata katalog kartu dalam penyusunannya juga sangat memakan waktu dan membutuhkan banyak tenaga. Karena rumitnya sistem katalog kartu maka pada tahun 1972 banyak melakukan instalasi komputer.

Dengan perkembangan teknologi informasi katalog juga mengalami perkembangan menjadi katalog online atau katalog OPAC. Dimana semua pekerjaan pengolahan bahan pustaka kini semakin dipermudah, tanpa memerlukan banyak tempat, praktis dan efisien serta mampu mengakses data-data secara cepat dan tepat, juga tidak membutuhkan banyak tenaga. Dengan katalog online informasi yang diperlukan akan muncul pada layar komputer dan untuk menyampaikan kepada pemakai bahan pustaka apa yang dimiliki perpustakaan 
serta untuk mencari kembali bahan pustaka tertentu dalam koleksi perpustakaan, katalog merupakan alat pencari yang terpenting.

OPAC adalah pangkalan data yang berisikan cantuman bibliografi yang dirancang untuk dapat diakses melalui terminal (komputer) sehingga pemakai dapat langsung dan secara efektif mencari dan menemukan kembali informasi yang dibutuhkan tanpa bantuan staff. ${ }^{1}$

Menurut ALA Glosary of Library and Information Science menjelaskan bahwa OPAC adalah cantuman bibliografi dalam bentuk yang dapat dibaca oleh mesin dan disimpan dalam sistem komputer, pemakai dapat mengakses informasi secara terus menerus dengan pendekatan pengarang, judul, subjek, ISBN, atau gabungan dari komponen-komponen yang disebutkan.

Jadi, tujuan dan fungsi OPAC adalah untuk memberi kepuasan kepada pengguna dalam mempercepat pencarian informasi sesuai representsi pertanyaan yang dibutuhkan serta menemu-kembalikan informasi yang relevan yang tersedia di perpustakaan, juga sebagai sarana untuk mengetahui status suatu bahan pustaka dan lokasi bahan pustaka tersebut.

Begitu berkembang pesatnya teknologi diera sekarang sehingga manusia semakin dipermudah aktifitasnya, inilah pesan al-Qur'an dalam QS. al-Lail ayat ketujuh:

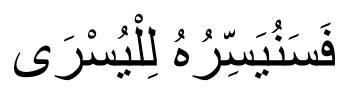

Terjemahnya:

"Maka kami kelak akan menyiapkan baginya jalan yang mudah". 2

Namun dari penjelasan teori diatas tentang fungsi dan tujuan OPAC sangat berbanding terbalik dengan kenyataan yang terjadi di perpustakaan, dimana masih banyak pemustaka yang tidak menggunakan OPAC sebagai sistem temu balik informasi menggunakan mesin pencari katalog online. Pemustaka lebih memilih menggunakan cara konvensional yaitu menelusuri koleksi dengan cara mendatangi langsung koleksi yang ada di rak buku. Untuk menelusuri koleksi secara langsung dirak buku itu lebih banyak waktu yang dikeluarkan, karena harus ditelusuri dari tiap rak, setelah itu baru mulai masuk penelusuran koleksi yang diinginkan, dari koleksi satu kekoleksi yang lain sampai pada penemuan koleksi yang diinginkan.

OPAC menawarkan akses secara online ke koleksi perpustakaan melalui terminal komputer untuk menelusuri informasi, tetapi kenyataannya justru terminal komputer yang sudah terhubung dengan internet disalah gunakan,

${ }^{1}$ Penggunaan katalog online (OPAC), http:// www.blogger. com / post-create.g? blog $\underline{\mathrm{ID}=6691702132305951291}$. Diakses dari internet tanggal 26/06/2012.

${ }^{2}$ Departemen Agama RI, op. cit., QS, Al-Lail (92):7., h. 596. 
bukannya untuk menelusuri koleksi yang tersedia di perpustakaan tetapi malah digunakan untuk online facebook.

\section{TINJAUAN TEORETIS}

\section{a. Katalog Perpustakaan}

Katalog perpustakaan adalah cantuman atau daftar koleksi dari suatu perpustakaan, atau daftar koleksi dari banyak perpustakaan yang terhubung secara elektronik. Ketika daftar koleksi dari banyak perpustakaan digabungkan, maka daftar tersebut disebut union catalog atau katalog induk yang dapat diakses bersama oleh berbagai perpustakaan. Katalog perpustakaan dapat juga dikatakan sebagai daftar yang tersusun dari sumber-sumber informasi yang disusun berdasarkan urutan-urutan yang logis atau yang telah di tetapkan, pada dasarnya dibuat oleh perpustakaan dengan maksud agar pemakai perpustakaan dapat menemukan kembali bahan pustaka yang dibutuhkan yang telah tersimpan diperpustakaan. ${ }^{3}$

Bahan pustaka yang didaftar dalam suatu catalog mencerminkan kepemilikan suatu perpustakaan, dan apabila ditambah dengan daftar koleksi dari perpustakaan lain, maka katalog tersebut disebut katalog induk atau katalog yang diakses bersama oleh sejulah perpustakaan. Jenis bahan pustaka yang dimaksudkan dalam katalog adalah buku, periodical atau serial termaksud jurnal profesional atau majalah populer, surat kabar dan berbagai jenis publikasi lainnya yang diterbitkan secara berseri, pamflet, bahan audio-visual, file komputer dan informasi digital.

1) Fungsi Katalog

- Menyatakan tentang apa yang dimiliki oleh perpustakaan

- Membantu pemakai melakukan seleksi dengan tepat

- Untuk menyediakan akses terhadap item bahan pustaka

- Sebagi alat bagi staf perpustakaan yang ditempatkan pada bagian pengadaan, pengatalogan, pengawasan inventaris, dan bagian reverensi. ${ }^{4}$

2) Jenis Katalok:

- Katalog buku

- Katalog kartu

- COM (Computer Output Microform)

- OPAC (Online Public Acces Catalogue )

- CD-ROM (Compact Disk Read Only Memory) catalog. ${ }^{5}$

\footnotetext{
${ }^{3}$ Irvan Muiyadi. Pengatalogan dan klasifikasi untuk tenaga teknis perpustakaan (Cet.1: Makassar: Alauddin press. 2011), h. 13

${ }^{4}$ Irvan Muliyadi, op. cit., h.16.
} 


\section{b. Pengertian Online Public Acces Catalogue (OPAC)}

OPAC adalah pangkalan data yang berisikan cantuman bibliografi yang dirancang untuk dapat diakses melalui terminal (komputer) sehingga pemakai dapat langsung dan secara efektif mencari dan menemukan kembali informasi yang dibutuhkan tanpa bantuan staff. ${ }^{6}$ OPAC disediakan untuk membantu pengguna perpustakaan dalam mencari dokumen dan untuk memenuhi kebutuhan pengguna dalam memecahkan suatu pertanyaan atau permintaan dengan cepat dan tepat. ${ }^{7}$ OPAC merupakan sarana penyimpanan, sarana penelusuran informasi secara online, dan sebagai sarana untuk memeriksa status dari suatu bahan pustaka.

Dalam "Dictionary of Library and Information Management" menyebutkan bahwa OPAC adalah sistem katalog perpustakaan berbasis elektronik yang bisa digunakan melalui terminal komputer untuk mencari informasi atau koleksi. ${ }^{8}$

Menurut Horgan (1994) menyatakan Online Public Acces Catalogue (OPAC) adalah suatu sistem temu balik informasi, dengan satu sisi masukan (input) yang menggabungkan pembuatan file yang tercantum dan indeks, pengguna dapat menggunakan OPAC untuk menjawab permintaan atau pertanyaan tertentu dan menjadi salah satu sarana atau alat bantu untuk menelusuri informasi di perpustakaan yang menggunakan sistem komputer yang terpasang jaringan LAN (Local Area Network). ${ }^{9}$

\section{c. Tujuan dan Fungsi Online Public Access Catalogue (OPAC)}

OPAC merupakan sarana mutakhir yang telah menjadi pilihan utama perpustakaan selain memberikan kemudahan bagi pengguna. OPAC juga memberi kemudahan bagi petugas perpustakaan dalam melakukan kegiatan pengatalogan dan lain-lain. Peralihan katalog manual ke bentuk online, disamping banyak menghemat waktu pengguna dalam penelusuran, juga mampu meningkatkan efisiensi pekerjaan pengatalogan bahan pustaka baru. Katalog elektronik terbukti juga mampu mempromosikan koleksi perpustakaan sehingga penggunanya semakin tinggi. Tujuan lain menyatakan:

5 Ibid., h.17.

6 Penggunaan katalog online (OPAC), http:// www.blogger. com / post-create.g? blog $\underline{I D=6691702132305951291}$. Diakses dari internet tanggal 26/06/2012.

${ }^{7}$ Arif Ikhwan, Online Publice Acce Catalogue. (Yogyakarta: Media Informasi, 2005) hal. 20

${ }^{8}$ Janet Stevenson, Dictionary of Library and Information Management. ( Michigan: Collin, 1997)

${ }^{9}$ Geral Patrick,Horgan,Staff Use of Online Public Access Catalogues (OPAC). (University Library: Wales, 1994). 
1) Pemustaka dapat mengakses secara langsung ke dalam pangkalan data yang dimiliki perpustakaan.

2) Mengurangi beban biaya dan waktu yang diperlukan dan yang harus dikeluarkan oleh pengguna dalam mencari informasi.

3) Mengurangi beban pekerjaan dalam pengelolaan pangkalan data sehingga dapat meningkatkan efisiensi tenaga kerja.

4) Mempercepat pencarian informasi.

5) Dapat melayani kebutuhan informasi masyarakat dalam jangkauan luas.

Dari penjelasan di atas dapat dinyatakan bahwa tujuan penyediaan OPAC di perpustakaan adalah untuk memberi kepuasan kepada pengguna dan staf perpustakaan dan mempercepat pencarian informasi yang tersedia di perpustakaan. OPAC difungsikan untuk membantu pengguna di dalam sistem temu kembali informasi di suatu perpustakaan. Selain sebagai sistem temu kembali informasi OPAC juga berfungsi sebagai sarana untuk mengetahui status suatu bahan pustaka dan lokasi bahan pustaka tersebut. OPAC mempunyai kemampuan untuk menyediakan bantuan kepada pengguna dengan lebih mudah dibandingkan dengan katalog kartu, bukan hanya lebih banyak titik akses yang bisa diakses tetapi OPAC lebih fleksibel.

Hadirnya OPAC di perpustakaan dapat memberikan keuntungan bagi pustakawan atau staff perpustakaan dan juga pemustaka, diantaranya:

1) Dapat menelusur koleksi perpustakaan lebih cepat (efisien) dibanding dengan katalog kartu.

2) Mempercepat pekerjaan katalogisasi dan klasifikasi.

3) Mengecek buku ada di perpustakaan atau sedang dipinjam.

4) Memesan buku yang akan dipinjam.

5) Mengetahui buku yang sedang dipinjam

Katalog adalah keterangan singkat atau wakil dari suatu dokumen. Katalog terhubung adalah jantung dari sebuah sistem perpustakaan yang terautomasi. Akan tetapi perpustakaan masih banyak yang menggunakan katalog kartu. Adapun alasan menggunakan katalog kartu yaitu : data koleksi lama belum dimasukan seluruhya dalam komputer. Katalog kartu dipertahankan karena mahalnya harga perangkat kerasnya dan kebanyakan perpustakaan belum sanggup untuk mengadakan komputer dalam jumlah yang sepadan dengan jumlah pengunjungnya. Akan tetapi katalog yang terautomasi menawarkan lebih banyak kelebihan bila dibandingkan dengan katalog kartu. Subsistem lain seperti OPAC dan sirkulasi berinteraksi dengan komputer dalam menyediakan layanan automasi. Sebuah sistem katalog yang dirancang dengan baik merupakan faktor kunci keberhasilan penerapan automasi perpustakaan. Sistem temu balik informasi yang disediakan memberikan kemudahan kepada para pengguna utuk mendapatkan koleksi-koleksi apa yang diinginkannya. Pada perpustakaan yang sudah 
melakukan automasi sistem temu balik informasi yang digunakan adalah OPAC (Online Public Acces Catalogue ). Menurut Markey, pengguna lebih menyukai OPAC daripada kartu katalog karena : a) Menelusur di OPAC menyenangkan, b) Menelusur di OPAC menghemat waktu, c) OPAC menyediakan layanan baru, dan d) OPAC menyediakan ciri khas yang baru.

\section{d. Model Penelusuran}

Dalam penelusuran informasi di sistem temu kembali informasi, terdapat macam cara untuk memperoleh informasi yang relevan yaitu dengan menggunakan penelusuran Bolean. George Boole menggunakan tiga operator, yaitu,$+ X$, -, untuk mengombinasikan pernyataan. Logica Booliean terungkap melalui apa yang dikenal sebagai diagram venn, yaitu:

1) Irisan, Menggunakan Operator AND. Dua diskriptor harus ada dalam dokumen yang diindeks, artinya dokumen tersebut diindeks dalam dua diskriptor. Contoh: Filsafat AND Islam.

2) Pengepungan (Inclusion) menggunakan Operator OR. Kedua deskriptor terdapat pada dokumen yang diindeks. Contoh Filsafat OR Islam.

3) Ekslusif atau Exclusion menggunakan operator NOT. Operator ini digunakan untuk meniadakan deskriptor lain. Contoh: Filsafat NOT Islam.

Jika dalam diagram Venn sebagai berikut:

1) Pengepungan atau inclusion atau jumlah mantiki (logical sum) Operator OR

2) Irisan atau intersention atau produk logis (logical produc) Operator AND

3) Ekslusif atau perbedaan mantiki (logical difference) Operator NOT

Selain yang tersebut diatas, untuk memperoleh informasi yang relevan dalam google penelusuran disebutkan dengan menggunakan tanda kutip ganda (“"), yaitu dengan menempatkan tanda kutip ganda dalam serangkaian kata untuk mempertimbangkan kata-kata yang tepat dalam urutan yang tepat juga, sebagai contoh "Filsafat Islam". Dengan tanda kutip ganda tersebut akan menghilangkan 'filsafat pendidikan Islam".

Inti dari proses temu kembali informasi pada OPAC adalah bagaimana kita dapat melakukan pencariam kembali terhadap dokumen yang kita simpan. Metode pengaksesan dan pencarian kembali dokuman akan mengikuti pendekatan proses penyimpanan yang kita pilih. Menggunakan database yang terintegrasi dengan baik membuat proses ini lebih fleksibel dan efektif dilakukan, terutama unyuk penyimpanan data dalam skala besar. Disisi lain, kelemahannya adalah relatif lebih rumitnya sistem dan proses yang harus kita lakukan. 
Database memang sangat menarik karena sifat pendekatan database yang memiliki kebebasan terhadap data (data independen). Dengan data yang sama kita bisa membuat interface keberbagai aplikasi lain baik yang berbasis stand alone dikomputer maupun aplikasi di web.

\section{METODOLOGI PENELITIAN}

Jenis penelitian yang digunakan adalah penelitian deskriptif yang akan memberikan gambaran mengenai bagaimana persepsi pemustaka terhadap Online Public Acces Catalogue (OPAC) di Perpustakaan Universitas Islam Negeri Alauddin Makassar. Lokasi penelitian yang berkaitan dengan pembahasan tersebut adalah di Perpustakaan Universitas Islam Negeri Alauddin Makassar yang terletak di Jalan H. Muh. Yasin Limpo, Romang Polong, Kabupaten Gowa. Objek penelitian yang dijadikan sebagai informan dalam mengumpulkan data yaitu mahasiswa yang berkunjung di Perpustakaan Universitas Islam Negeri Alauddin Makassar. Sedangkan sumber data yang lain yang sifatnya non-insani berupa data kepustakaan (library research), seperti dokumen-dokumen, skripsi, buku, majalah dan lain-lain yang berkaitan dengan penelitian. Jadi sumber data yang dimaksud adalah subjek dari mana data dapat diperoleh, ${ }^{10}$.

Dalam penelitian ini penulis menggunakan beberapa metode pengumpulan data, yaitu: observasi, interview, dan dokuemntasi. Instrumen penelitian adalah catatan observasi, pedoman wawancara, dan chek list dokumentasi. Data yang diperoleh melalui teknik tersebut diolah oleh penulis dengan menggunakan metode sebagai berikut:

1) Menyusun suatu daftar permasalahan dalam bentuk pertanyaan dan disusun secara sistematis berdasarkan kerangka konseptual.

2) Menguraikan setiap pertanyaan untuk selanjutnya disusun menurut kebutuhan data dan berbagai perkiraan jawaban yang mungkin akan diberikan oleh para informan.

3) Mencantumkan suatu kode (coding) pada setiap pertanyaan bersamaan dengan jawaban dan informasi yang dilontarkan atau diberikan oleh para informan. Tanda tersebut berupa nama, status informan atau jawaban singkat. Ini dimaksudkan agar memudahkan pelacakannya termasuk untuk keperluan interpretasinya nanti.

4) Mengkaji setiap pertanyaan berikut kode dan keterangan jawaban yang hendak diintepretasi dalam bahasa baku menurut perspektif penulis.

5) Formulasi-formulasi yang telah dirumuskan sedemikian rupa tersebut, dituangkan ke dalam susunan yang saling berangkai dalam bentuk

${ }^{10}$ Suharsimi Arikunto, Prosedur Penelitian: Suatu Pendekatan Praktek (Jakarta: Rineka Cipta, 1993), h. 102. 
pertanyaan deskriptif yang siap disajikan sebagai sebuah pembahasan tesis yang representative.

Model analisis data yang digunakan dalam penelitian ini adalah model interaktif yang dikembangkan oleh Miles dan Huberman yang dimulai dengan pengumpulan data, reduksi data, penyajian data, dan penarikan kesimpulan/verifikasi. ${ }^{11}$ Proses analisis data dilakukan secara terus-menerus di dalam proses pengumpulan data selama penelitian berlangsung.

\section{HASIL PENELITIAN DAN PEMBAHASAN}

Perpustakaan UIN Alauddin Makassar merupakan salah satu perpustakaan perguruan tinggi yang telah menerapkan sistem otomasi berupa OPAC sebagai alat penelusuran katalog terpasang/online.

Berikut ini beberapa tanggapan pemustaka tentang OPAC di Perpustakaan UIN Alauddin Makassar: Menurut tanggapan Fajeruddin yang merupakan pemustaka di Perpustakaan UIN Alauddin Makassar:

"Fajeruddin mengatakan bahwa menggunakan bantuan sistem OPAC dalam mencari buku di perpustakaan cukup membantu, karena dengan sistem tersebut mempermudah penelusuran koleksi secara cepat tanpa membutuhkan banyak waktu. Hanya saja pustakawan kurang mensosialisasikan dan memberikan bimbingan kepada pemustaka tentang manfaat OPAC."

Hal serupa juga disampaikan oleh pemustaka lain:

Muh. Jasman, mengatakan bahwa penyediaan sistem OPAC di Perpustakaan UIN Alauddin Makassar cukup membantu, karena dapat meningkatkan kualitas layanan pada kecepatan pencarian koleksi serta merasa terbantu dengan hadirnya OPAC, selain mengefektifkan waktu penelusuran koleksi juga memberikan kenyamanan dalam mencari koleksi.

Sedangkan tanggapan lain yang berbeda dengan tanggapan diatas:

"Menurut Irsan Kadang jaringan tidak terkoneksi dengan OPAC sehingga menciptakan kemalasan bagi saya untuk menggunakan OPAC dan kadang sistem komputer tidak bertahan lama selalu ada kerusakan seperti mouse, keyboard,UPS,bahkan CPU kadang tiba-tiba mati, serta sekedar mengingatkan bahwa untuk menciptakan pelayanan yang prima dan

\footnotetext{
${ }^{11}$ Wahyu, Pedoman Penelitian Pendidikan (Bandung: Tarsito, 1996), h. 61.
} 
efisien agar semua sistem OPAC diaktifkan dan segala kerusakan tetap terjaga dan terawat."

Begitupun Syamsi seorang pemustaka, mengungkapkan masalah yang biasa didapatkannya saat menggunakan OPAC

"Kadang perbandingan tingkat perolehan koleksi dan ketepatan yang didapatkan melalui OPAC menunjukkan perolehan lebih tinggi tetapi ketepatan rendah. Saat itu saya menginginkan buku filsafat dan hasil yang didapatkan pada OPAC sangat banyak judul buku yang sama bahkan walaupun bukan judul buku filsafat juga ada tetapi untuk mendapatkan judul buku yang tepat sesuai yang diinginkan sangatlah kurang. Menurut saya untuk mendapatkan koleksi yang sama sangat banyak tetapi untuk mendapatkan koleksi yang tepat seperti yang diinginkan kurang.

Tanggapan lain yang disampaikan pemustaka, bahwa menurut:

"Kais sistem OPAC itu harusnya bebas akses secara online karena saya mahasiswa ingin mengetahui koleksi apa saja yang ada diperpustakaan yang bisa kami baca dan pinjam untuk menjadi referensi dalam mengerjakan tugas."

"Begitupun Dahniar seorang pemustaka yang aktif menggunakan jasa perpustakaan, selalu mendapatkan keluhan mati lampu disaat menggunakan OPAC, karena menurutnya OPAC sangat tergantung aliran listrik, bila listrik mati maka kegiatan penelusuran OPAC akan terganggu, jadi masukan bagi saya seharusnya pihak perpustakaan menyediakan cadangan listrik sebagai antisipasi ketika listrik akan padam, karena untuk menciptakan pelayanan teknologi informasi yang canggih harus didukung dengan fasilitas yang memadai."

\section{PENUTUP}

\section{a. Kesimpulan}

Mengacu pada pembahasan yang telah dipaparkan sebelumnya maka, dapat diambil kesimpulan sebagai berikut: Persepsi pemustaka tentang sistem otomasi berupa OPAC yaitu belum efektif pemanfaatannya sebagai alat penelusuran katalog terpasang/online di Perpustakaan UIN Alauddin Makassar. Hal ini disebabkan oleh pustakawan kurang mensosialisasikan dan memberikan bimbingan kepada pemustaka tentang manfaat OPAC, koneksi jaringan pada komputer OPAC kurang stabil sehingga pemustaka tidak dapat melakukan penelusuran dengan baik, buku yang ada dirak dengan hasil temuan pada mesin pencari OPAC tidak sesuai sehingga berefek pada rasa malas pemustaka untuk menggunakan OPAC, kurangnya ketelitian dalam proses penginputan huruf atau 
angka dokumen bahan pustaka pada sistem sehingga berakibat tidak ditemukannya dokumen bahan pustaka bila dicari pada mesin pencari OPAC.

\section{DAFTAR PUSTAKA}

A, Kent. Information Analysis and Retrieval. New York: Becker and Heys, 1971.

Departemen Agama RI. Al-Qur'an dan Terjemahannya. Ed. Revisi, Surabaya: Surya Agung, 2006.

Departemen Pendidikan dan Kebudayaan. Kamus Bahasa Indonesia. Cet. II; Jakarta : Balai Pustaka, 1990

Dini, Suhardi. Penerapan Teknologi Informasi Perpustakaan. Makalah yang disajikan pada Simposium Nasional Universitas Pendidikan Indonesia di Jakarta, 7-9 Februari 2001.

Feather, John. International Enciclopedia of Information and Library Science. London: Routledge, 1997

Handayaningrat, Soewarno. Pengantar Studi Umum Administrasi dan Manajemen. Jakarta: Gunung Agung, 1985.

Hasugian, Jonner. Penggunaan Bahasa Ilmiah dan Kosa Kata Terkendali dalam Sistem Temu Balik Informasi Berbasis Teks. Pustaha: (Jurnal Studi Perpustakaan dan Informasi).usupress.usu.ac.id/.../Pustaha\%20Vol_\%202\%20No_\%202\%20 Des_\%202006.pdf, di akses pada tanggal 3 Juni 2012

Horgan, Geral Patrick. Staff Use of Online Public Access Catalogues (OPAC). University Library: Wales, 1994

Husaebah, St. Pattah, et al., Buku Panduan Perpustakaan UIN Alauddin Makassar. Makassar: Alauddin Press, 2009.

Ikhwan, Arif. Online Publice Acce Catalogue. Yogyakarta: Media Informasi, 2005

Lasa, HS. Kamus Istilah Perpustakaan, Yogyakarta: Gadjah Mada Universitas, 1998

Markey, Karen. Thus Spake the OPAC User”, Information Technology and Libraries, March, 1993.

Muliyadi, Irvan. Pengatalogan dan klasifikasi untuk tenaga teknis perpustakaan. Cet.1: Makassar: Alauddin press, 2011 
Mustafa. Pengembangan Sistem Otomasi Perpustakaan. Makalah disampaikan dalam Pelatihan Otomasi Perpustakaan. Makassar: Politeknik Negeri Ujung Pandang, 2005.

Nurocman Arif. Teknologi Informasi Perpustakaan. Purwokerto: Jawa Tengah, 2010. http: // arifnurblog. Blogspot. Com. / 2010/ 04/ teknologi- informasiperpustakaan- vs. Html. 21 November 2010.

Oemar, Hamalik. Perencanaan Pengajaran Berdasarkan Pendidikan Sistem. Cet. 2; Jakarta : Bumi Aksara

Republik Indonesia. Undang-Undang Republik Indonesia Nomor 43 Tahun 2007 Tentang Perpustakaan, Jakarta: Perpustakaan Nasional RI, 2007.

Saleh, Abdull Rahman dkk. CDS/ISIS Panduan Pengolahan Sistem Manajemen Basis Data Untuk Perpustakaan. Jakarta: Sagung Seto, 2009

Setiawan, Agung. Pengantar Sistem Informasi. Bandung: Informatika, 2007

Sulistyo-Basuki. Pengantar Ilmu perpustakaan. Jakarta: Gramedia Pustaka Utama, 1992.

Stevenson, Janet Dictionary, of Library and Information Management. Michigan: Collin, 1997.

Sugiono. Metode Penelitian Administrasi, Cet.16; Bandung: Alfabeta, 2008

Suharsimi, Arikunto. Prosedur Penelitian Suatu Pendekatan Praktis. Jakarta: Bulan Bintang, 1989.

Surahman, Arif. Layanan Perpustakaan Berbasis Teknologi Informasi. Cet. 1; Jakarta: Bintang, 1999.

Sutanta, Edhy. Pengantar Teknologi Informasi. Yogyakarta: Graha Ilmu, 2005

Tatang M, Amarin. Pokok-pokok Teori Sistem. Cet. 6; Jakarta: Raja Grafindo Persada, 1992.

Universitas Islam Negeri Alauddin Makassar. Pedoman Penulisan Karya Tulis Ilmiah: Skripsi, Tesis, dan Disertasi. Cet. 2; Makassar: Alauddin Press, 2009.

Wahyu, Suprianto. Teknologi Informasi Perpustakaan Strategi Perencanaan Perpustakaan Digital. Yogyakarta, 2008. 